\title{
Carbonic Anhydrase III S-Glutathionylation Is Necessary for Anti-Oxidant Activity
}

\author{
P. Roy, M. Ireland, S. Roy, J. Craft, C. Bartholomew* \\ Department of Biological \& Biomedical Sciences, School of Health \& Life Sciences, Glasgow Caledonian University, \\ City Campus, Glasgow, UK \\ Email: *c.bartholomew@gcu.ac.uk
}

How to cite this paper: Roy, P., Ireland, M., Roy, S., Craft, J. and Bartholomew, C. (2018) Carbonic Anhydrase III S-Glutathionylation Is Necessary for Anti-Oxidant Activity. Yangtze Medicine, 2, 244-254.

https://doi.org/10.4236/ym.2018.24026

Received: August 10, 2018

Accepted: December 18, 2018

Published: December 21, 2018

Copyright (c) 2018 by authors and Scientific Research Publishing Inc. This work is licensed under the Creative Commons Attribution International License (CC BY 4.0).

http://creativecommons.org/licenses/by/4.0/

\section{cc) (7) Open Access}

\begin{abstract}
Carbonic anhydrase isozyme CA3 protects cells against oxidative stress. Ectopic expression of murine $\mathrm{Ca} 3$, but not $\mathrm{Ca} 2$, protects proto-oncogene Evi1 expressing Rat1 fibroblast cells (ca3low) against hydrogen peroxide $\left(\mathrm{H}_{2} \mathrm{O}_{2}\right)$ induced stress. $\mathrm{Ca} 3$ is S-glutathionylated via glutathione adducts with cysteines 181 and 186. Substitution of both Ca3 cysteines with serine fails to protect cells from oxidative stress. Insertion of cysteine at 181 and 186 in $\mathrm{Ca} 2$ is insufficient for conferring efficient anti-oxidant activity. This shows for the first time that S-glutathionylation of cys181 and cys186 residues is required for $\mathrm{Ca} 3$ anti-oxidant activity but that additional factors are also required.
\end{abstract}

Keywords

CA3, CAIII, Carbonic Anhydrase III, S-Glutathionylation, Apoptosis, Anti-Oxidant

\section{Introduction}

Intracellular $\mathrm{pH}$ is partly regulated by a family of carbonic anhydrase (CA, EC4.2.1.1) enzymes that reversibly catalyse the hydration of carbon dioxide to bicarbonate and hydrogen ions [1]. The $\alpha$-CAs comprise 15 distinct zinc metalloenzymes that can be sub-divided into cytoplasmic (CAI, CAII, CAIII, CAVII, CAXIII), membrane bound (CAIV, CAIX, CAXII, CAXIV, CAXV), mitochondrial (CAV), non-catalytic (CAVIII, CAX, CAXI) and secreted (CAVI) [2]. These ubiquitous enzymes are of significant importance for many physiological processes and are implicated in various pathological conditions including atherosclerosis [3], retinitis pigmentosa [4], myasthenia gravis [5] and cancer [6].

Carbonic anhydrase III (CA3) is unique in this family as it has low hydratase activity [7] but it is very abundant in liver, skeletal muscle and adipose tissue. 
However, surprisingly for such an abundant protein (e.g. $2 \%$ of wet weight in slow oxidative muscle (type 1) [8]) its function remains an enigma. Until recently Ca3KO mice were believed to lack any functional deficit [9] but have now been shown to display impaired mitochondrial ATP synthesis [10]. In addition, these mice show changes in expression of genes involved in oxidative stress [11]. This implies CA3 might participate in the cellular response to oxidative stress.

There is mounting evidence that strongly suggests CA3 is an anti-oxidant. Tissue in which it is abundant is those whose metabolic activity results in considerable oxidative stress, including aerobic respiration in skeletal muscle and lipid metabolism in adipose tissue. CA3 expression is co-induced with established anti-oxidant genes such as superoxide dismutase following endurance training in elite athletes when skeletal muscle is exposed to increased oxidative stress [12] [13].

Functional molecular evidence, in addition to the associated expression studies above, shows that CA3 has anti-oxidant activity. Enforced CA3 expression in NIH3T3 cells protects them from hydrogen peroxide $\left(\mathrm{H}_{2} \mathrm{O}_{2}\right)$-induced apoptosis [14]. EVI1 proto-oncoprotein transformed Rat1 fibroblasts have repressed ca3 expression and either transgene mediated restoration of $\mathrm{Ca} 3$ in these cells or direct RNAi mediated $\mathrm{Ca} 3 \mathrm{KD}$ in parental Rat1 cells (high endogenous ca3) protects and sensitizes cells to $\mathrm{H}_{2} \mathrm{O}_{2}$ induced apoptosis respectively [15]. Insight into a possible mechanism of CA3 anti-oxidant activity has been obtained from post-translational modification observed in cells during oxidative stress. CA3 is modified by S-glutathionylation in response to t-butylhydroperoxide or menadione in cultured hepatocytes [16] as well as in stressed skeletal muscle [11]. Crystal structure studies and site directed mutagenesis reveal two cysteine residues, cys181 and cys186, are available for the addition of glutathione adducts via transient formation of oxidised cysteine sulfenic acid intermediates [17] [18].

S-glutathionylation of CA3 is believed to help protect and aid recovery of cells from the damaging effects of oxidative agents. Previous studies showing that CA3 has anti-oxidant activity and that the protein is S-glutathionylated has led to speculation that the two processes are connected [18]. Direct functional evidence for this is lacking. In this study advantage is taken of our previous analysis in Rat1 fibroblast cells [15]. Derivative Evil proto-oncoprotein expressing Rat1 fibroblast cells, designated 5.61, have low ca3 and increased sensitivity to oxidative stress but become resistant upon restoration of ca3 levels by ectopic expression of Ca3. 5.61 cells are used here to explore the relationship between CA3 S-glutathionylation and CA3 anti-oxidant activity.

\section{Materials \& Methods}

\section{Cell Culture}

Rat1 fibroblast cells and Evil expressing Rat1 cell population 5.61 cells have been described previously [15]. Rat1 and 5.61 cells were cultured in complete 
medium (CM) comprising Dulbecco's Modified Eagle's Medium (Lonza Group Ltd, Basel, Switzerland, BE12-604F) supplemented with 5\% newborn calf serum (Sigma-Aldrich, Poole, UK, N4637) and $2.5 \mathrm{mM}$ glutamine, $50 \mu \mathrm{g} / \mathrm{ml}$ penicillin, 50 units/ml streptomycin (Lonza Group Ltd., BE17-605E \& BE17-603E), 500 $\mu \mathrm{g} / \mathrm{ml} \mathrm{G} 418$ (5.61 cells only, Invitrogen, Paisley, UK), $37^{\circ} \mathrm{C}, 5 \% \mathrm{CO}_{2}$. For hydrogen peroxide $\left(\mathrm{H}_{2} \mathrm{O}_{2}\right)$ treatment, cells were incubated in $\mathrm{CM}$ supplemented with $750 \mathrm{mM} \mathrm{H}_{2} \mathrm{O}_{2}$ (Sigma-Aldrich, 21676) for $16 \mathrm{hrs.}$

\section{Preparation of Plasmid DNA}

Plasmids pCMVsport6Ca3 (I.M.A.G.E. Id 4195712), pCMVsport6Ca2 (I.M.A.G.E. Id 6479187) and pRLCMV have all been described previously (Source Bioscience, geneservice, Cambridge, UK; Stratagene, La Jolla, CA, USA). Plasmid DNA's were prepared by affinity chromatography using Nucleobond ${ }^{\oplus}$ PC500EF gravity flow columns according to manufacturer's instruction (Macherey-Nagal GmbH \& Co. Kg, Düren, Germany).

\section{Site Directed Mutagenesis}

Point mutations of $\mathrm{Ca} 2$ and $\mathrm{Ca} 3$ gene sequences were created by Quick Change $^{\mathrm{TM}} \mathrm{XL}$ site directed mutagenesis using either pCMVsport6Ca2 or pCMVsport6Ca3 DNA, according to the manufacturer's instructions (Agilent technologies, USA). Briefly, 50 ng of plasmid DNA was mixed with $125 \mathrm{ng}$ forward and reverse primers, $1 \mu \mathrm{dNTP}$ 's, Pfu Turbo DNA polymerase (2.5 U) in $50 \mu \mathrm{l}$ and incubated $95^{\circ} \mathrm{C}, 30 \mathrm{sec}$ then 14 cycles of $95^{\circ} \mathrm{C} 30 \mathrm{sec}, 55^{\circ} \mathrm{C} 1 \mathrm{~min}$ followed by $68^{\circ} \mathrm{C} 6 \mathrm{~min}$ in a programmable thermocycler (MJ Scientific, Hampton, New Hampshire, USA, PTC-100). N186C (Ca2) and C181S (Ca3) mutant plasmid DNA's were used as template for site directed mutagenesis to create double mutants S181CN186C (Ca2) and C181SC186S (Ca3) respectively. Oligonucleotide primers for site directed mutagenesis were designed using the site directed mutagenesis primer design tool (Agilent technologies) and synthesized by Integrated DNA Technologies (BVBA, Leuven, Belgium). Ca2 S181C FP:

GCTAACTTTGATCCTTGCTGCCTTCTTCCTGGAAAC; Ca2 S181C RP: GTTTCCAGGAAGAAGGCAGCAAGGATCAAAGTTAGC; Ca2 N186C FP: TTGCTCCCTTCTTCCTGGATGCTTGGACTACTGGACATAT; Ca2 N186C RP: ATATGTCCAGTAGTCCAAGCATCCAGGAAGAAGGGAGCAA;

Ca2 S181CN186C FP:

GATCCTTGCTGCCTTCTTCCTGGATGCTTGGACTAC; Ca2 S181CN186C RP: GTAGTCCAAGCATCCAGGAAGAAGGCAGCAAGGA

TC; Ca3 C181S FP: TTTTACACACTTTGACCCATCAAGCC

TGTTCCCTGCTTGCCG; Ca3 C181S RP:

CGGCAAGCAGGGAACAGGCTTGA

TGGGTCAAAGTGTGTAAAA; Ca3 C186S FP:

CATGCCTGTTCCCTGCTAGCC

GGGACT; Ca3 C186S RP: AGTCCCGGCTAGCAGGGAACAGGCATG;

Ca3 C181SC186S FP:

CAAGCCTGTTCCCTGCTAGCCGGGACTATTGGACCT 


\section{ACC; Ca3 C181SC186S RP:}

\section{GGTAGGTCCAATAGTCCCGGCTAGCAGGGAACAGGCTTG.}

\section{Sequencing}

Point mutation of $\mathrm{Ca} 2$ and $\mathrm{Ca} 3$ gene sequences were verified by partial sequencing of plasmid DNA (DNA Analysis Facility, Human Genetics Unit, Ninewells Hospital, Dundee, UK). DNA sequence analysis was performed using FinchTV version 1.4.0.

\section{DNA Mediated Transfection}

5.61 cells were transfected with $1 \mu \mathrm{g}$ plasmid DNA using Fugene6 ${ }^{\circledR}$ (Roche Diagnostics GmbH, Mannheim, Germany, 11815091001). $1 \times 10^{5}$ cells were incubated with a 1:6 ratio DNA: FuGENE6 ${ }^{\oplus}$, prepared as described by the manufacturer, for $48 \mathrm{hrs}$.

Caspase 3 Assay

Cells were incubated in 96 well dishes (Costar 3917) and apoptosis determined by the Caspase $3 / 7-\mathrm{Glo}^{\circ}$ assay according to the manufacturer's instructions (Promega, G8090), measuring luminescence with a Fluostar OPTIMA luminometer (BMG LABTECH).

\section{Western Blot Analysis}

Protein extracts, SDS polyacrylamide gel electrophoresis and western blotting were performed as described previously [15] with either $\alpha$-ca3 (Santa Cruz Biotechnology Inc., Santa Cruz, CA, USA, E-19), $\alpha$-ca2 (Santa Cruz Biotechnology Inc, Santa Cruz, CA, USA, C-10) or $\alpha$-gapdh (Fitzgerald Industries, North Acton, MA, USA, 6C5) and diluted 1/1000 (E-19), 1/200 (C-10) or 1/5000 (6C5). Appropriate HRP conjugated $\alpha$-goat (Sigma-Aldrich, A5420) or $\alpha$-mouse (Sigma-Aldrich, A9044) IgG secondary antibodies were used at 1/5000 dilutions and detection was performed by enhanced chemiluminescence (Pierce, Rockford, IL, USA, 32209).

\section{Statistical Analysis}

Statistical significance was determined by two-way ANOVA using GraphPad PRISM $^{\circ} 7.0 \mathrm{c}$ software. $\mathrm{P} \leq 0.05$ was considered significant.

\section{Results}

\section{Ca3 but not $\mathrm{Ca} 2$ protects cells from oxidative stress}

Murine $\mathrm{Ca} 2$ and $\mathrm{Ca} 3$ proteins show $60 \%$ amino acid identity (Figure 1). Initially we examined and compared the anti-oxidant activity of these two proteins in cells. Evil transformed Rat1 cells (5.61) were chosen for this purpose as they have previously been shown to express low levels of ca3 [15] and they are -ve for ca2. Both genes were transiently expressed for $48 \mathrm{hrs}$ in 5.61 cells using pCMVsport6Ca2 and pCMVsport6Ca3 expression vectors as described in materials and methods. Western blot analysis with $\alpha$-ca3 (Santa Cruz E-19) antibodies shows elevated levels of $\mathrm{Ca} 3$ in pCMVsport6Ca3 transfected 5.61 cells relative to parental (UT) or empty vector (pRCCMV) transfected cells (Figure 2(a)). Similarly, western blot analysis with $\alpha$-ca2 (Santa Cruz D-8) shows abundant 
YDPGSAKTILNNGKTCRVVFDDTFDRSMLRGGPLSGPYRLRQFHLHWGSS 100 --KVAS-S-V---HSFN-E---SQ-FAV-KE-----S---I---F----- 100

DDHGSEHTVDGVKYAAELHLVHWNPKYNTFGEALKQPDGIAVVGIFLKIG 150 -GQ------NKK------------T--GD--K-VQH------L------- 150

REKGEFQILLDALDKIKTKGKEAPFNHFDP,CHFPCRDWTYHGSFTTP 200 PASQGL-KITE--HS------R-A-AN---CS-L-GNL-----P--L--- 200

PCEECIVWLLLKEPMTVSSDQMAKLRSLFASAENEPPVPLVGNWRPPQPI 250 -LL--VT--V----I----E--SHF-K-NFNS-G-AEELM-D----A--- 250

KGRVVRASEK 260

-N-KIK---- 260

Figure 1. Comparison of the primary amino acid sequence of murine Ca2 (Accession number NM_009801) and Ca3 (Accession number NM_007606) proteins. Identity of amino acid sequences are indicated using the single letter code. Regions of $\mathrm{Ca} 2$ identical with $\mathrm{Ca} 3$ are indicated by -. Cysteine residues 181 and 186, present in Ca3 but absent from $\mathrm{Ca} 2$ are highlighted by a boxed $\mathrm{C}$ in bold.

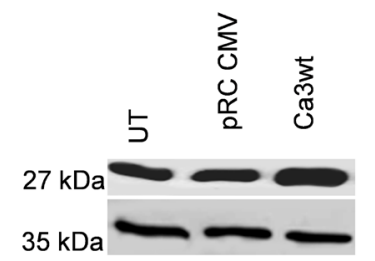

(a)

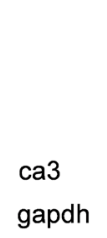

gapdh

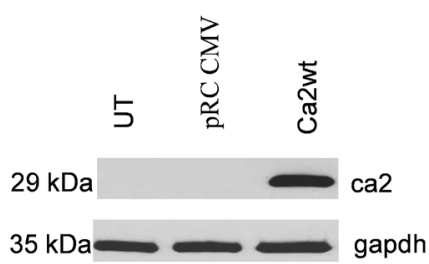

(b)

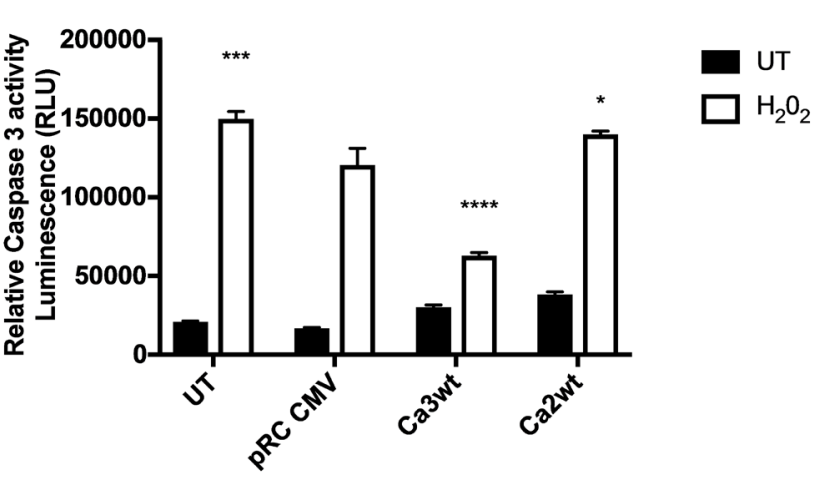

(c)

Figure 2. Caspase 3 activity in $\mathrm{H}_{2} \mathrm{O}_{2}$ treated 5.61 cells with enforced expression of Ca2 and $\mathrm{Ca} 3$. (a) and (b) show representative examples of western blot analysis of whole cell extracts derived from untransfected (UT) 5.61 cells or 5.61 cells transfected with empty vector (pRC CMV), Ca2 (Ca2wt) or Ca3 (Ca3wt) expression vectors for 48 hrs with $\alpha$-ca2 (C-10), $\alpha$-ca3 (E-19) and $\alpha$-gapdh (6C5) antibodies. The expected $29 \mathrm{kDa} \mathrm{Ca} 2,27 \mathrm{kDa}$ $\mathrm{Ca} 3$ and $35 \mathrm{kDa}$ gapdh proteins are indicated; (c) shows a histogram of relative caspase 3 catalytic activity in untransfected (UT), empty vector (pRC CMV) transfected and Ca2 (Ca2wt) or Ca3 (Ca3wt) overexpressing 5.61 cells + (white columns) or - (black columns) $16 \mathrm{hrs} \mathrm{H}_{2} \mathrm{O}_{2}$. Histogram is the mean value of three measurements and the error bars the SEM. Statistical analysis shows two-way ANOVA and Dunnetts multiple comparisons test of $\mathrm{H}_{2} \mathrm{O}_{2}$ treated $\mathrm{pRC} \mathrm{CMV}$ vs $\mathrm{UT}$ or Ca3wt or Ca2wt, ${ }^{\star} \mathrm{P}<0.05,{ }^{* *} \mathrm{P}<$ $0.001,{ }^{* * *} \mathrm{P}<0.0001$. 
$\mathrm{Ca} 2$ protein in pCMVsport6Ca2 transfected 5.61 cells which is absent from parental (UT) and empty vector (pRCCMV) transfected cells (Figure 2(b)). In each case, western blot analysis with $\alpha$-gapdh (Santa Cruz 6C5) confirmed even loading of proteins.

Next, we investigated the anti-oxidant activity of $\mathrm{Ca} 2$ and $\mathrm{Ca} 3$ in 5.61 cells. Cells were transiently transfected with $\mathrm{Ca} 2$ or $\mathrm{Ca} 3$ expression vectors as described above and then treated with $750 \mu \mathrm{M} \mathrm{H} \mathrm{H}_{2} \mathrm{O}_{2}$ for $16 \mathrm{hrs} . \mathrm{H}_{2} \mathrm{O}_{2}$ induced apoptosis was examined by measuring caspase 3 catalytic activity as described in materials and methods. Ca2, Ca3 or empty vector control cells all show low caspase 3 catalytic activity in the absence of $\mathrm{H}_{2} \mathrm{O}_{2}$ treatment (Figure 2(c)). Caspase 3 catalytic activity is induced in each case following $\mathrm{H}_{2} \mathrm{O}_{2}$ treatment but is significantly less in $\mathrm{Ca} 3$ expressing cells (Figure 2 (c), pRC CMV vs Ca3wt, ${ }^{* * * *} \mathrm{P}<$ $0.0001)$. In contrast, $\mathrm{Ca} 2$ expression does not protect 5.61 cells from $\mathrm{H}_{2} \mathrm{O}_{2}$ induced apoptosis (Figure 2(c), Ca2wt). These data confirm that $\mathrm{Ca} 3$ protects cells from oxidative stress induced apoptosis and that this property is not shared by the $\mathrm{Ca} 2$ isozyme.

Cysteines 181 and 186 are necessary for $\mathrm{Ca} 3$ anti-oxidant activity in Rat1 cells

Reversible oxidative stress induced ca3 S-glutathionylation occurs on cysteine residues 181 and 186 [18]. A full length wild type (wt) Ca3genecDNA in pCMVsport 6 was mutated by site directed mutagenesis (materials \& methods) to encode Ca3serine at position 181 (Ca3C181S), Ca3serine at position 186 (Ca3C186S) single mutant or Ca3 serine at position 181 and 186 (Ca3C181SC186S) double mutant proteins, that have previously been shown to inhibit S-glutathionylation [18]. To confirm their expression, the wt and mutant Ca3 proteins were each transiently over-expressed by transfection of the various constructs in 5.61 cells. Western blot analysis of whole cell extracts derived from the transfected cells with $\alpha$-ca3 shows over-expression of wt and mutant $27 \mathrm{KDa} \mathrm{Ca} 3$ proteins in transfected cells (Figure $3(\mathrm{a})$ ) relative to the endogenous protein in empty vector transfected 5.61 cells (Figure 3(a), pRCCMV). In each case, western blot analysis with $\alpha$-gapdh confirmed even loading of proteins.

The mutant $\mathrm{Ca} 3$ proteins were next examined for anti-oxidant activity. 5.61 cells transiently transfected with constructs encoding either wt or mutant Ca3 proteins were examined for caspase 3 catalytic activity (materials and methods) either with or without $750 \mu \mathrm{M} \mathrm{H}_{2} \mathrm{O}_{2}$ treatment for $16 \mathrm{hrs}$. The results show low caspase 3 enzyme catalytic activity is significantly induced following exposure to $\mathrm{H}_{2} \mathrm{O}_{2}$ in each case (Figure $3(\mathrm{~b})$ ). As before, there is a highly significant reduction in caspase 3 enzyme catalytic activity in cells with enforced expression of wt Ca3 (Figure 3 (b) pRC CMV vs Ca3wt, ${ }^{* * *} \mathrm{P}<0.0001$ ) confirming anti-oxidant activity. However, the $\mathrm{H}_{2} \mathrm{O}_{2}$ induced caspase 3 enzyme catalytic activity is induced to either a greater (Figure 3 (b) pRC CMV vs UT ${ }^{* * *} \mathrm{P}<0.0001$ or Ca3C181S ${ }^{*} \mathrm{P}<0.01$ or Ca3C186S ${ }^{*} \mathrm{P}<0.01$ ) or similar extent (Figure $3(\mathrm{~b}) \mathrm{pRC}$ CMV vs Ca3C181SC186S) in all other cells that are either untransfected (UT) or 


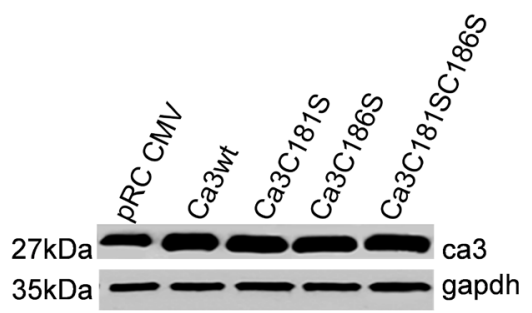

(a)

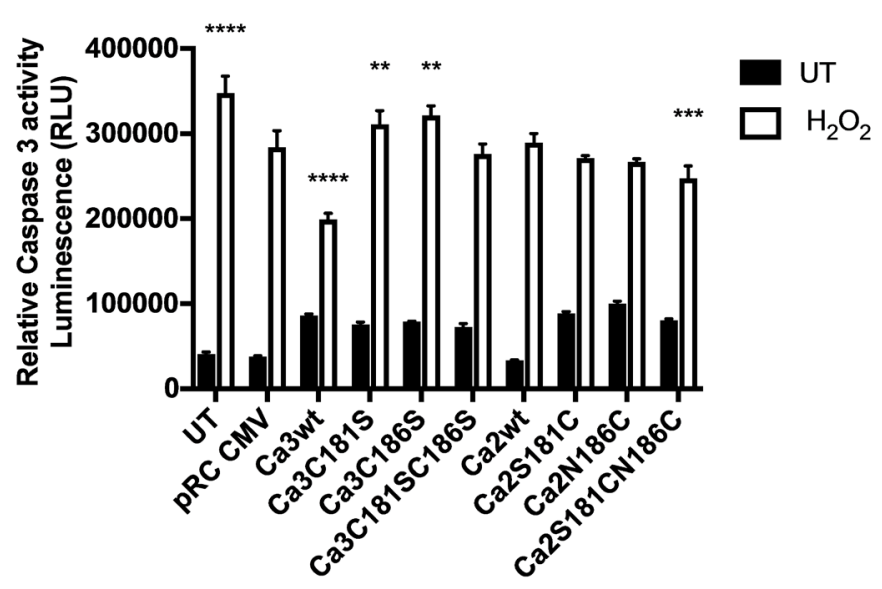

(b)

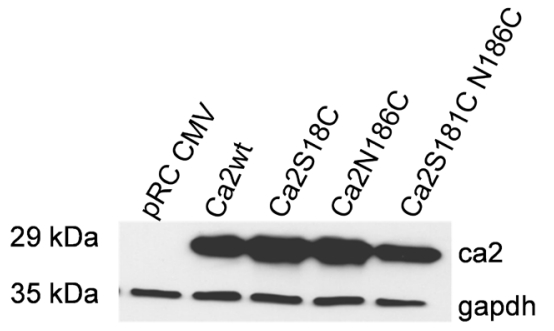

(c)

Figure 3. Caspase 3 activity in $\mathrm{H}_{2} \mathrm{O}_{2}$ treated 5.61 cells with enforced expression of Ca3 and $\mathrm{Ca} 2$ encoding wt, cysteine 181 and 186 mutant proteins. (a) shows western blot analysis of whole cell extracts derived from transfected 5.61cells with the empty vector control pRC CMV or over expressing the indicated Ca3wt and mutant proteins. The antibodies used and the Ca3 and gapdh proteins detected are as indicated in figure legend 2; (b) shows a histogram of relative caspase 3 catalytic activity in untransfected (UT), empty vector (pRC CMV), Ca3wt, indicated Ca3 cysteine mutant, Ca2wt and indicated Ca2 serine or asparagine mutant overexpressing 5.61 cells + (white columns) or - (black columns) $16 \mathrm{hrs} \mathrm{H}_{2} \mathrm{O}_{2}$. Histogram is the mean value of three measurements and the error bars the SEM. Statistical analysis shows two-way ANOVA and Dunnetts multiple comparisons test of $\mathrm{H}_{2} \mathrm{O}_{2}$ treated pRC CMV vs UT or Ca3wt or C181S or C186S or C181SC186S or Ca2wt or Ca2S181C or Ca2N186C or Ca2S181CN186C, ${ }^{* \star} \mathrm{P}<0.01,{ }^{* * *} \mathrm{P}$ $<0.001,{ }^{* * *} \mathrm{P}<0.0001$.

transfected with one of the three Ca3 mutant proteins. This shows mutant Ca3proteins are no longer protective in Rat1 cells exposed to oxidative stress.

Cysteines 181 and 186 are insufficient to confer anti-oxidant activity on $\mathrm{Ca} 2$ in Rat1 cells 
The Ca2 amino acids serine 181 (Ca2S181C) and asparagine 186 (Ca2N186C) were converted to cysteine residues, by site directed mutagenesis of pCMVsport6Ca2 expression vector DNA, to see if this would confer anti-oxidant activity on the $\mathrm{Ca} 2$ protein. Ca2wt, Ca2S181C, Ca2N186C single mutant and Ca2S181CN186C double mutants were each transiently expressed in 5.61 cells (materials and methods). Western blot analysis of cell extracts with $\alpha$-ca2 shows the presence of similar amounts of the expected wt and mutant $29 \mathrm{KDa}$ proteins in transiently transfected cells which is absent from cells transfected with the empty vector control (Figure $3(\mathrm{c})$ ). In each case, western blot analysis with $\alpha$-gapdh confirmed even loading of proteins (Figure $3(\mathrm{c})$ ). The mutant Ca2 proteins were examined for antioxidant activity in $\mathrm{H}_{2} \mathrm{O}_{2}$ treated cells as before. No significant difference was observed in $\mathrm{H}_{2} \mathrm{O}_{2}$ induced caspase 3 catalytic activity when compared to empty vector control (pRC CMV) cells (Figure 3(b)) but there was a minor but significant reduction with the double mutant protein (Figure 3 (b) pRC CMV vs Ca2S181CN186C $\left.{ }^{* * *} \mathrm{P}<0.001\right)$.

\section{Discussion}

It is now widely accepted that CA3 undergoes S-glutathionylation [19] and that this post-translational modification is elevated by either chemical [16] [20], including $\mathrm{H}_{2} \mathrm{O}_{2}$ [21] or exercise [11] mediated oxidative stress in cultured cells and intact tissues in various mammalian species examined. X-ray crystallography shows that both rat ca3 and S-glutathionylated ca3 are structurally very similar and that two surface exposed cysteine residues (C181 and C186) participate in adduct formation [17]. Substitution of both C181 and C186 for serine completely abolishes S-glutathionylation of Ca3 [18]. We show in this study that Ca3 $\mathrm{C} 181$ and $\mathrm{C} 186$ are both essential for in vivo $\mathrm{Ca} 3$ anti-oxidant activity and that S-glutathionylation is therefore an essential feature of the mechanism by which this protein participates in protecting cells from oxidative stress.

Mutation of either C181, C186 or both to serine residues are equally effective at inhibition of $\mathrm{Ca} 3$ anti-oxidant activity. Previous studies show that C186 is preferentially S-glutathionylated relative to C181, suggesting that this residue might be more important in anti-oxidant activity [18]. However, the same studies also show that the efficiency of C186 S-glutathionylation is significantly reduced in the $\mathrm{C} 181$ mutant $\mathrm{Ca} 3$ protein (70\% reduction). These observations are consistent with our results that mutation of either one or both of these cysteine residues to encode a serine has a significant impact on Ca3 biological activity as an anti-oxidant.

Our results also confirm previous studies [14] that the closely related $\mathrm{Ca} 3$ protein, $\mathrm{Ca} 2$, does not share anti-oxidant activity. Furthermore, we show that the introduction of cysteines at positions 181 and 186 of the Ca2 protein is insufficient to confer anti-oxidant activity although there is a minor increase in the presence of both residues. This result suggests other factors, which might impact on the efficiency of S-glutathionylation, are required for anti-oxidant activity. 
The S-glutathionylated cysteine residues in $\mathrm{Ca} 3$ have a low $\mathrm{pKa}[18]$ and S-glutathionylation is affected positively and negatively by lysine 211 and glutamic acid 188/aspartic acid 212 respectively. The pKa of the cysteine residues in mutant $\mathrm{Ca} 2$ have not been determined, however the lysine, aspartic acid and glutamic acid amino acids are conserved in Ca2. The S-glutathionylation process can occur spontaneously (reviewed in [22]) but can be catalysed. Glutathione-S-Transferase $\pi$ (GSTP) catalyses S-glutathionylation of both 1-CYS peroxiredoxin [23] and cardiac aldose reductase [24]. Homozygous KO mice depleted of GSTP show a general reduction in oxidative stress induced protein S-glutathionylation [25] suggesting this protein might be involved in conjugation of glutathione to other proteins, including Ca3. Therefore, there might be other molecular determinants of Ca3 S-glutathionylation besides C181 and C186 that are absent from Ca2.

The CA3 C181 and C186 residues are conserved in all mammalian species examined, including human, rat, murine and bovine, but only C181 is found in xenopus and neither residues are observed in chicken or zebrafish (data not shown). This suggests that only mammalian CA3 has evolved anti-oxidant activity, but this would need to be tested experimentally as other cysteine residues might be S-glutathionylated in non-mammalian species. For example, the CA3 isozyme CAVII is also S-glutathionylated but at cysteine residues C183 and C217 [26].

\section{Acknowledgements}

This work is funded by a Glasgow Caledonian University $\mathrm{PhD}$ studentship and Overseas Research Student Award Scheme (PR).

\section{Conflicts of Interest}

The authors declare no conflict of interest.

\section{References}

[1] Liang, J.Y. and Lipscomb, W.N. (1988) Hydration of CO2 by Carbonic Anhydrase: Intramolecular Proton Transfer between $\mathrm{Zn} 2+$ Bound $\mathrm{H} 2$ and Histidine 64 in $\mathrm{Hu}-$ man Anhydrae II. Biochemistry, 27, 8676-8682.

https://doi.org/10.1021/bi00423a025

[2] Lehtonen, J., Shen, B., Vihinen, M., Casini, A., Scozzafava, A., Supuran, C.T., Parkkila, A.K., Saarnio, J., Kivelä, A.J., Waheed, A., Sly, W.S. and Parkkila, S. (2004) Characterization of CA XIII, a Novel Member of the carbonic Anhydrase Isozyme Family. Journal of Biological Chemistry, 279, 2719-2727. https://doi.org/10.1074/jbc.M308984200

[3] Park, J.Y., Seong, J.K. and Paik, Y.K. (2004) Proteomic Analysis of Diet-Induced Hypercholesterolemic Mice. Proteomics, 4, 514-523. https://doi.org/10.1002/pmic.200300623

[4] Datta, R., Waheed, A., Bonapace, G., Shah, G.N. and Sly, W.S. (2009) Pathogenesis of Retinitis Pigmentosa Associated with Apoptosis-Inducing mutations in Carbonic Anhydrase IV. Proceedings of the National Academy of Sciences of the United 
States of America, 106, 3437-3442. https://doi.org/10.1073/pnas.0813178106

[5] Du, A.L., Ren, H.M., Lu, C.Z., Tu, J.L., Xu, C.F. and Sun, Y.A. (2009) Carbonic Anhydrase III Is Insufficient in Muscles of Myasthenia Gravis Patients. Autoimmunity, 42, 209-215. https://doi.org/10.1080/08916930802668610

[6] Dai, H.Y., Hong, C.C., Liang, S.C., Yan, M.D., Lai, G.M., Cheng, A.L. and Chuang, S.E. (2008) Carbonic Anhydrase III Promotes Transformation and Invasion Capability in Hepatoma Cells through FAK Signaling Pathway. Molecular Carcinogenesis, 47, 956-963. https://doi.org/10.1002/mc.20448

[7] Jewell, D.A., Tu, C.K., Paranawithana, S.R., Tanhauser, S.M., LoGrasso, P.V., Laipis, P.J. and Silverman, D.N. (1991) Enhancement of the Catalytic Properties of Human Carbonic Anhydrase III by Site-Directed Mutagenesis. Biochemistry, 30, 1484-1490. https://doi.org/10.1021/bi00220a006

[8] Carter, N.D. (1991) Hormonal and Neuronal Control of Carbonic Anhydrase III Gene Expression in Skeletal Muscle. In: Dodgson, S.J., Tashian, R.E., Gross, G. and Carter, N.D., Eds., The Carbonic Anhydrases. Cellular Physiology and Molecular Genetics, Plenum Publishing Corp., New York, 247-256.

https://doi.org/10.1007/978-1-4899-0750-9_21

[9] Kim, G., Lee, T.H., Wetzel, P., Geers, C., Robinson, M.A., Myers, T.G., Owens, J.W., Wehr, N.B., Eckhaus, M.W., Gros, G., Wynshaw-Boris, A. and Levine, R.L. (2004) Carbonic Anhydrase III Is Not Required in the Mouse for Normal Growth, Development, and Life Span. Molecular and Cellular Biology, 24, 9942-9947. https://doi.org/10.1128/MCB.24.22.9942-9947.2004

[10] Liu, M., Walter, G.A., Pathare, N.C., Forster, R.E. and Vandenborne, K. (2007) A Quantitative Study of Bioenergetics in Skeletal Muscle Lacking Carbonic Anhydrase III Using 31P Magnetic Resonance Spectroscopy. Proceedings of the National Academy of Sciences of the United States of America, 104, 371-376. https://doi.org/10.1073/pnas.0609870104

[11] Zimmerman, U.J., Wang, P., Zhang, X., Bogdanovich, S. and Forster, R. (2004) Anti-Oxidative Response of Carbonic Anhydrase III in Skeletal Muscle. IUBMB Life, 56, 343-347. https://doi.org/10.1080/1521-6540400000850

[12] Zoll, J., Ponsot, E., Dufour, S., Doutreleau, S., Ventura-Clapier, R., Vogt, M., Hoppeler, H., Richard, R. and Flück, M. (2006) Exercise Training in Normobaric Hypoxia in Endurance Runners. III. Muscular Adjustments of Selected Gene Transcripts. Journal of Applied Physiology, 100, 1258-1266. https://doi.org/10.1152/japplphysiol.00359.2005

[13] Shang, X., Chen, S., Ren, H., Li, Y. and Huang, H. (2009) Carbonic Anhydrase III: The New Hope for the Elimination of Exercise-Induced Muscle Fatigue. Medical Hypotheses, 72, 427-429. https://doi.org/10.1016/j.mehy.2008.10.027

[14] Räisänen, S.R., Lehenkari, P., Tasanen, M., Rahkila, P., Härkönen, P.L. and Väänänen, H.K. (1999) Carbonic Anhydrase III Protects Cells from Hydrogen Peroxide-Induced Apoptosis. FASEB Journal, 13, 513-522.

https://doi.org/10.1096/fasebj.13.3.513

[15] Roy, P., Reavey, E., Rayne, M., Roy, S., Abed El Baky, M., Ishii, Y. and Bartholomew, C. (2010) Enhanced Sensitivity to Hydrogen Peroxide-Induced Apoptosis in Evi1 Transformed Rat1 Fibroblasts Due to Repression of carbonic Anhydrase III. FEBS Journal, 277, 441-452. https://doi.org/10.1111/j.1742-4658.2009.07496.x

[16] Chai, Y.C., Hendrich, S. and Thomas, J.A. (1994) Protein S-Thiolation in Hepatocytes Stimulated by t-Butyl Hydroperoxide, Menadione, and Neutrophils. Archives of Biochemistry and Biophysics, 310, 264-272. 
https://doi.org/10.1006/abbi.1994.1166

[17] Mallis, R.J., Poland, B.W., Chatterjee, T.K., Fisher, R.A., Darmawan, S., Honzatko, R.B. and Thomas, J.A. (2000) Crystal Structure of S-Glutathiolated Carbonic Anhydrase III. FEBS Letters, 482, 237-241. https://doi.org/10.1016/S0014-5793(00)02022-6

[18] Kim, G. and Levine, R.L. (2005) Molecular Determinants of S-Glutathionylation of Carbonic Anhydrase 3. Antioxidants \& Redox Signaling, 7, 849-854. https://doi.org/10.1089/ars.2005.7.849

[19] Chai, Y.C., Jung, C.H., Lii, C.K., Ashraf, S.S., Hendrich, S., Wolf, B., Sies, H. and Thomas, J.A. (1991) Identification of an Abundant S-Thiolated Rat Liver Protein as Carbonic Anhydrase III; Characterization of S-Thiolation and Dethiolation Reactions. Archives of Biochemistry and Biophysics, 284, 270-278. https://doi.org/10.1016/0003-9861(91)90295-T

[20] Lii, C.K., Chai, Y.C., Zhao, W., Thomas, J.A. and Hendrich, S. (1994) S-Thiolation and Irreversible Oxidation of Sulfhydryls on Carbonic Anhydrase III during Oxidative Stress: A Method for Studying Protein Modification in Intact Cells and Tissues. Archives of Biochemistry and Biophysics, 308, 231-239.

https://doi.org/10.1006/abbi.1994.1033

[21] Mallis, R.J., Hamann, M.J., Zhao, W., Zhang, T., Hendrich, S. and Thomas, J.A. (2002) Irreversible Thiol Oxidation in Carbonic Anhydrase III: Protection by S-Glutathiolation and Detection in Aging Rats. Biological Chemistry, 383, 649-662. https://doi.org/10.1515/BC.2002.067

[22] Gallogly, M.M. and Mieyal, J.J. (2007) Mechanisms of Reversible Protein Glutathionylation in Redox Signaling and Oxidative Stress. Current Opinion in Pharmacology, 7, 381-391. https://doi.org/10.1016/j.coph.2007.06.003

[23] Manevich, Y., Feinstein, S.I. and Fisher, A.B. (2004) Activation of the Antioxidant Enzyme 1-CYS Peroxiredoxin Requires Glutathionylation Mediated by Heterodimerization with pi GST. Proceedings of the National Academy of Sciences, 101, 3780-3785. https://doi.org/10.1073/pnas.0400181101

[24] Wetzelberger, K., Baba, S.P., Thirunavukkarasu, M., Ho, Y.S., Maulik, N., Barski, O.A., Conklin, D.J. and Bhatnagar, A. (2010) Postischemic Deactivation of Cardiac Aldose Reductase: Role of Glutathione S-Transferase P and Glutaredoxin in Regeneration of Reduced Thiols from Sulfenicacids. The Journal of Biological Chemistry, 285, 26135-26148. https://doi.org/10.1074/jbc.M110.146423

[25] Townsend, D.M., Manevich, Y., He, L., Hutchens, S., Pazoles, C.J. and Tew, K.D. (2009) Novel Role for Glutathione S-Transferase pi. Regulator of Protein S-Glutathionylation Following Oxidative and Nitrosative Stress. The Journal of Biological Chemistry, 284, 436-445. https://doi.org/10.1074/jbc.M805586200

[26] Truppo, E., Supuran, C.T., Sandomenico, A., Vullo, D., Innocenti, A., Di Fiore, A., Alterio, V., De Simone, G. and Monti, S.M. (2012) Carbonic Anhydrase VII Is S-Glutathionylated without Loss of Catalytic Activity and Affinity for Sulfonamide Inhibitors. Bioorganic \& Medicinal Chemistry Letters, 22, 1560-1564.

https://doi.org/10.1016/j.bmcl.2011.12.134 